\title{
Current cost of medical negligence in NHS hospitals: analysis of claims database
}

\author{
Paul Fenn, Stephen Diacon, Alastair Gray, Ron Hodges, Neil Rickman
}

\begin{abstract}
Objectives To identify trends in the incidence and cost of clinical negligence claims. To determine the current annual cost to the NHS as a whole in terms of cash paid out to patients and their solicitors and the defence costs incurred.

Design Analysis of records on database.

Setting A well defined group of hospitals within one health authority which collected information on a consistent basis over many years.

Main outcome measures Data on individual claims.

Trends in incidence of claims and costs identified independently from organisational reforms and changes in accounting practices.

Results The rate of litigation increased from 0.46 to 0.81 closed claims per 1000 finished consultant episodes between 1990 and 1998. Overall expenditure on clinical negligence by the NHS in England in 1998 was estimated at $£ 84$ million (95\% confidence interval $£ 48$ million to $£ 130$ million).

Conclusions After adjustment for hospital activity, the rate of closed claims increased during the 1990s by about $7 \%$ per annum, a substantial rate of growth but not the uncontrolled explosion sometimes alluded to in the wider media. More coordination and openness are needed in data collection.
\end{abstract}

\section{Introduction}

In the $B M J$ in 1994 , Fenn et al reported an estimate of $£ 52.3$ million for the cost of hospital negligence claims borne by the NHS in the financial year 1990-1. ${ }^{1}$ This figure, which was based on a survey of 142 out of 190 district health authorities in 1991, was subsequently confirmed as accurate in a parliamentary answer by the secretary of state. ${ }^{2}$ Since then both the cost and incidence of negligence claims are widely believed to have soared in the wake of restructuring of the health service and NHS indemnity, by which process the financial responsibility for clinical negligence has been shifted to the provider hospitals and away from the individual clinicians. This process has itself, however, caused considerable difficulties for the estimation of the full NHS cost of clinical negligence since the early 1990s. Not only has there been a progressive transfer of liabilities from the district health authorities to the NHS trusts (each of which have separate accounting procedures) but also the trusts' liabilities have been spread since the creation of the clinical negligence scheme for trusts (CNST) and the existing liability scheme (ELS).

Untangling this knot is not straightforward, and a series of increasingly vague and imprecise estimates of the overall cost of negligence to the NHS during the 1990s has recently been documented. ${ }^{3}$ This has culminated in the (mis)use by the press of the auditor general's figure of £2.8 billion as an indicator of the amount "spent or still owed" on clinical negligence by the
NHS. ${ }^{4}$ Part of the problem arises from the separate sources of financial accounts and part from the consequent change in accounting procedures from a cash to an accruals basis. Most recently, the comptroller and auditor general has required trusts to report financial provisions for negligence, net of contributions from the clinical negligence scheme for trusts and the existing liability scheme as well as gross. ${ }^{5}$ The lack of clarity over the incidence and cost of litigation has important implications for management of clinical risk in the NHS.

We report results from a continuing database of clinical negligence claims. We explored individual claims data from a well defined group of hospitals within a given geographical area which have collected information on a consistent basis over many years. We identified trends in incidence of claims and costs independently from the nature of the defendant's legal identity or the accounting practice in place to estimate the likely cost of clinical negligence to the NHS in England overall.

\section{Methods and data}

We accessed and formatted a database, consisting of a full record of all negligence claims arising from treatment in Oxfordshire Health Authority. The health authority had a population of 610000 people in 1998, with a population density of 234 per square kilometre compared with 378 in England. Compared with the figures for England, in Oxfordshire Health Authority $16 \%$ versus $18 \%$ of the population is of pensionable age; the standardised mortality ratio is 88 versus 98 ; the annual rate of admission to hospital is 160 versus 172 per 1000 ; and $5 \%$ versus $9 \%$ of the population aged 16 years or over is on income support. ${ }^{67}$ In other words, the health authority is relatively affluent and healthy but with pockets of deprivation and demographically is fairly representative.

The database covers one major teaching hospital, several general/acute hospitals, and some specialist units. Claims were brought against the health authority (from events before restructuring) or the constituent NHS trusts (from events after restructuring). The database was established in the early 1980s and has been continuously maintained since then. Data on each claim are collected from the date of the initial incident, including details of the plaintiff, all claim events (disclosure, witness statements, expert reports, etc), and outcomes (payments made, costs incurred). As of January 1999 the database contained information on 902 active and 1993 closed clinical negligence cases. The advantage of using this database is that the trends in the incidence, disposition, and costs of claims within this representative area can be used to indicate national trends.

\author{
University of \\ Nottingham \\ Business School, \\ Nottingham \\ NG7 2RD \\ Paul Fenn \\ economist \\ Stephen Diacon \\ director of centre for \\ risk and insurance \\ studies \\ Ron Hodges \\ accountant \\ Health Economics \\ Research Centre, \\ Department of \\ Public Health, \\ University of \\ Oxford, Institute of \\ Health Sciences, \\ Headington, \\ Oxford OX3 7LF \\ Alastair Gray \\ director \\ Department of \\ Economics, \\ University of \\ Surrey, Guildford, \\ Surrey GU2 5XH \\ Neil Rickman \\ economist \\ Correspondence to: \\ P Fenn \\ paul.fenn@ \\ nottingham.ac.uk
}

BMJ 2000;320:1567-71 


\section{Results}

Volume of litigation, 1974-98

Figure 1 reports the annual number of opened and closed claims in the authority as a whole for the entire period over which data were consistently collected. In general, the trends show a pattern of steady growth in both new and closed claims, with the latter lagging behind the former by about three years. Moreover, this growth has continued since 1990, with the volume of litigation in 1998 (126 claims closed) more than twice the level at the beginning of the decade ( 55 claims closed in 1990), implying an annual rate of growth in closed claims of about $11 \%$. However, over the same period hospital activity grew by about $3.5 \%$ per annum in the health authority and nationally (from 8.78 million to 11.53 million finished consultant episodes in England in 1990 and 1998, respectively). Thus the rate of closed cases per 1000 finished consultant episodes has increased from about 0.46 in 1990 to 0.81 in 1998, a rate of increase of about $7 \%$ per annum. This growth in litigation has occurred across the range of medical

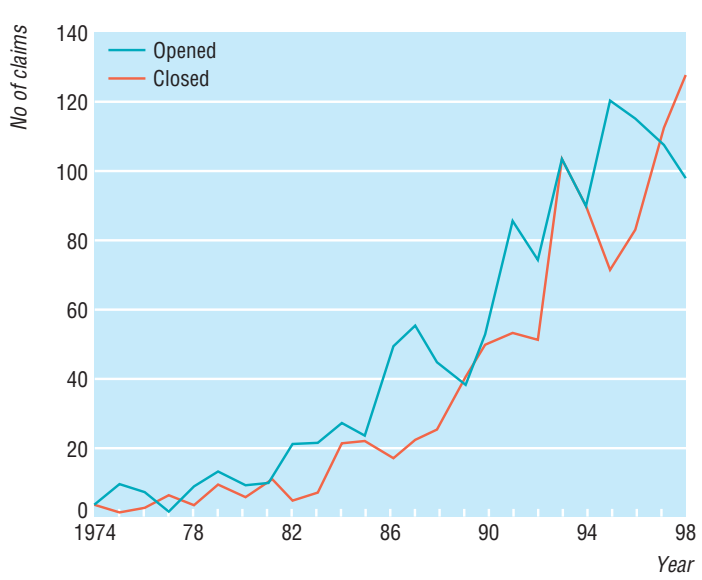

Fig 1 Opened and closed claims for medial negligence, Oxfordshire Health Authority, 1974-98

specialties, although the most pronounced growth has been in claims arising from obstetrics and gynaecology. Figure 2 shows the pattern of opened claims by major specialty over the period $1974-98$ in the authority.

While all the claims shown in figures 1 and 2 arose from events in hospitals within the area, the nature of the defendant changed over time: from the district health authority (in conjunction perhaps with the clinician's medical defence organisation) to the trusts, once they attained self governing status. This shift in liability is shown in figure 3 .

Clearly, the volume of litigation in the health authority area has been progressively transferred through the decade from the district to the trusts, to the point that most new and closed claims are now brought against trusts. During this period of transition the financial responsibility for meeting the costs of these claims has been split, and this gives the clearest illustration of why it has been difficult to track total NHS expenditure on clinical negligence since the early 1990s.

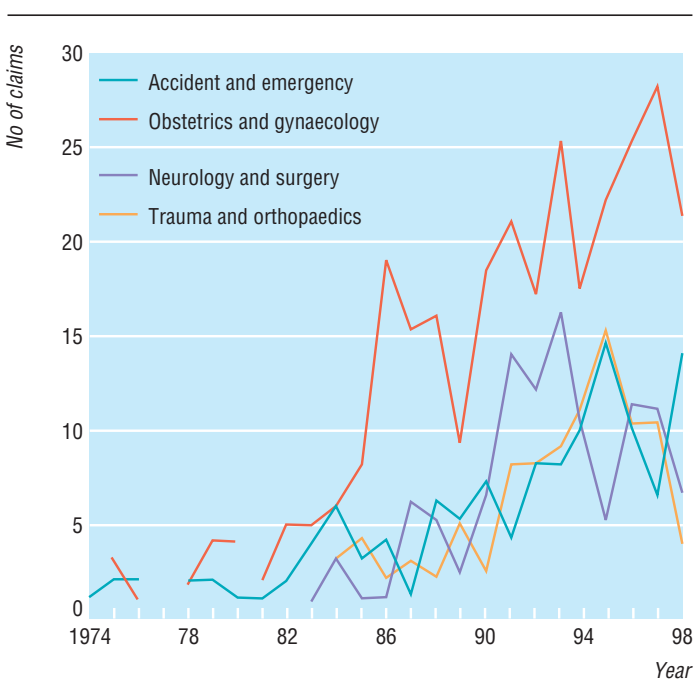

Fig 2 Opened claims by medical specialty, Oxfordshire Health Authority, 1974-98

Finally, to confirm whether Oxfordshire Health Authority is representative of the experience of clinical negligence in the country as a whole, we compared our observed incidence of claims in 1998 with that from a recently obtained (1998-9) representative sample of 61 English trusts, providing some $25 \%$ of all activity. ${ }^{8}$ In the latter sample, the rate of paid claims reported was 0.24 per 1000 finished consultant episodes, similar to the rate of 0.23 among the trusts in Oxfordshire (that is, after exclusion of claims paid by the district health authority).

\section{Cost of claims, 1974-98}

Of course, the closure of a claim does not necessarily imply a cost to the NHS, as many negligence claims have little chance of succeeding in court and are closed without payment to the plaintiff. Figure 4 shows the number of paid claims per annum together with the average gross payment made to the plaintiff (including legal costs). The number of paid claims is substantially lower than the number of closed claims: on average, only around $30 \%$ of claims succeed in obtaining compensation. Moreover, because there are relatively few

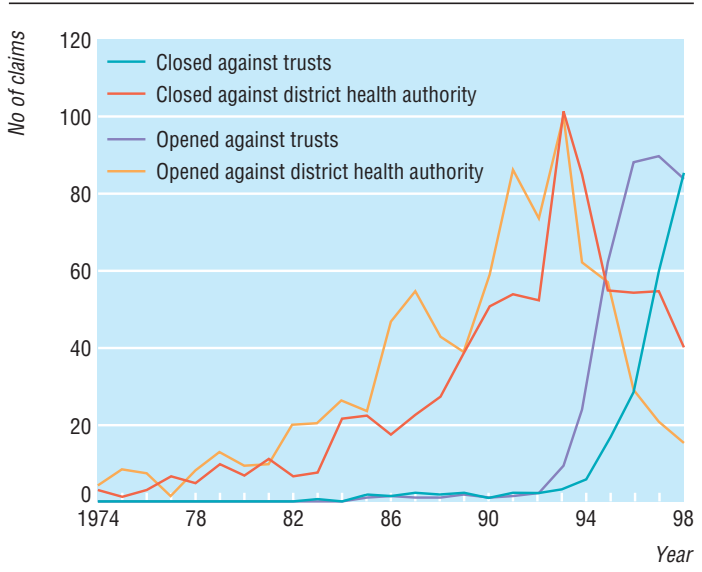

Fig 3 Opened and closed claims by defendant, Oxfordshire Health Authority 
claims that result in high damage settlements, the mean payment in any given year is highly unpredictable. The annual payment per paid claim since 1990 has averaged around $£ 20000$, but the annual average has been as high as $£ 50000$ and as low as $£ 4000$, reflecting the impact of large but infrequent settlements. For claims settled in 1998, the total amount paid out to plaintiffs and their solicitors was £1 092000 .

In addition, whether or not a payment was made to the plaintiff or the solicitor, the authority or the trust typically incurred defence costs for each claim in the form of payments to defence solicitors and counsel, together with expenses for expert witnesses. The mean total defence cost per claim is shown in figure 5, which shows clearly the effect of the move to NHS indemnity after 1990, after which the NHS bore the full burden of defence rather than sharing it with the medical defence organisations as was the case before 1990 .

The average legal cost to the NHS of defending a negligence claim more than doubled to over $£ 2000$ per claim during this period as a result of this indemnification of doctors by the NHS. The total amount paid out on defence costs for the claims that were closed in 1998 came to $£ 250560$.

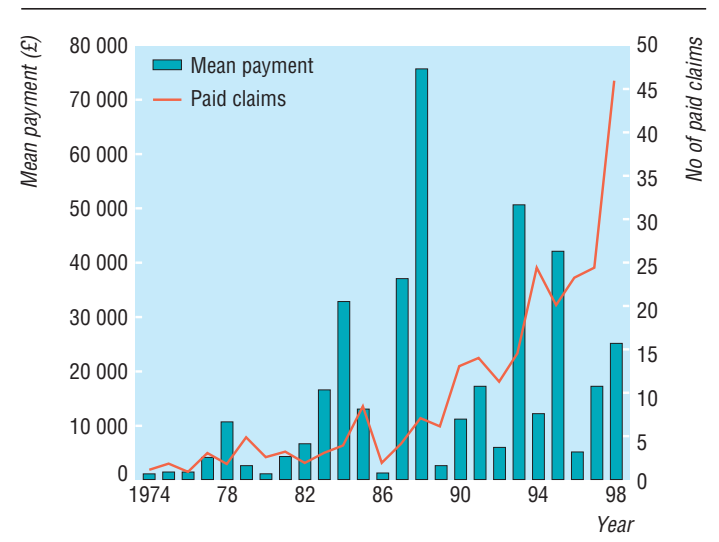

Fig 4 Paid claims and mean payment, Oxfordshire Health Authority

\section{Outstanding claims at the end of 1998}

Claims that were still open at the end of 1998 represent the future liabilities faced by the district health authority and by the trusts, for which some provisions must be made in the respective accounts. Figure 6 shows how these outstanding claims can be attributed to the years in which they were initiated. As of 1 January 1999 there were 81 claims outstanding against the authority and 169 against the trusts. Given that trusts have been liable for clinical negligence only since 1992, the "vintages" of their stock of open claims are relatively recent compared with the authority stock. Information on the claims managers' estimates of the likely settlement value is available for most of these claims. The average estimate per claim (for total damages and legal costs) was $£ 165836$ for the authority (reflecting the more severe nature of long duration claims) and £27 790 for the trusts. These estimates are used as the basis from which provisions for clinical negligence are calculated in the trusts' and authority's annual accounts. If all of the outstanding claims were provided for to the full extent of the estimate, this would produce a sum of $£ 4.7$ million outstanding liabilities for the trusts and

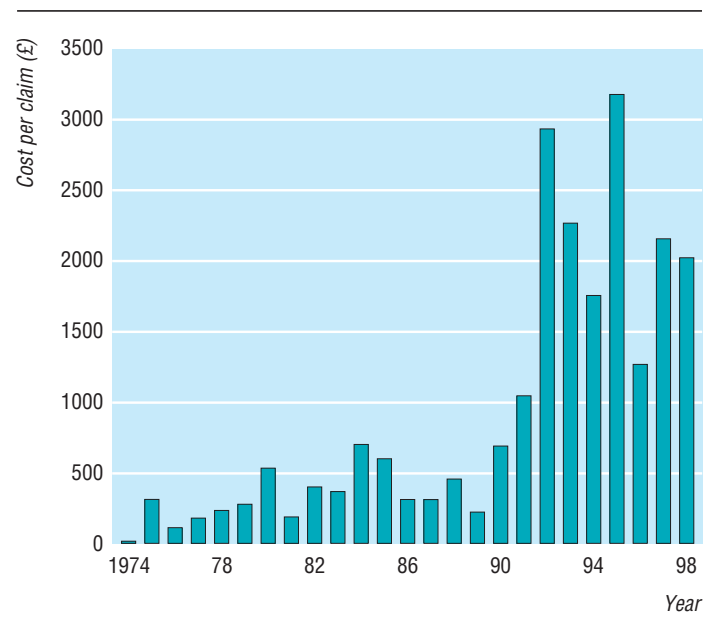

Fig 5 Mean defence costs (£),0xfordshire Health Authority

$£ 13.4$ million for the authority. In practice, of course, most of these outstanding claims are ultimately closed without payment, and, even when liability is fairly clear, the estimated settlement amount may be speculative.

\section{National estimates}

If we take into account all of the above trends and assume that Oxfordshire Health Authority is representative of the national picture we can estimate the current cost of clinical negligence to the NHS in England on a comparable basis with that adopted by Fenn et al in 1994 (that is, cash paid out). The combined rate at which claims were closed with payment by trusts and the health authority in Oxfordshire in 1998 was 0.29 (95\% confidence interval 0.21 to $0.37)$ per 1000 finished consultant episodes. The mean payment per claim, with data on 489 settlements from 1994-9, was $£ 18092$ ( $£ 13383$ to $£ 22800$ ). By using these estimates the expected NHS cost of clinical negligence per finished consultant episode is $£ 5.24$ ( $£ 2.74$ to £8.53). Given an estimated total number of finished consultant episodes in England of 11.53 million (Hospital Episode Statistics, 1997-8), a predicted range for England as a whole would be $£ 32$ million to $£ 99$ million, with a mean prediction of $£ 61$ million as the amount paid out by trusts and health authorities to

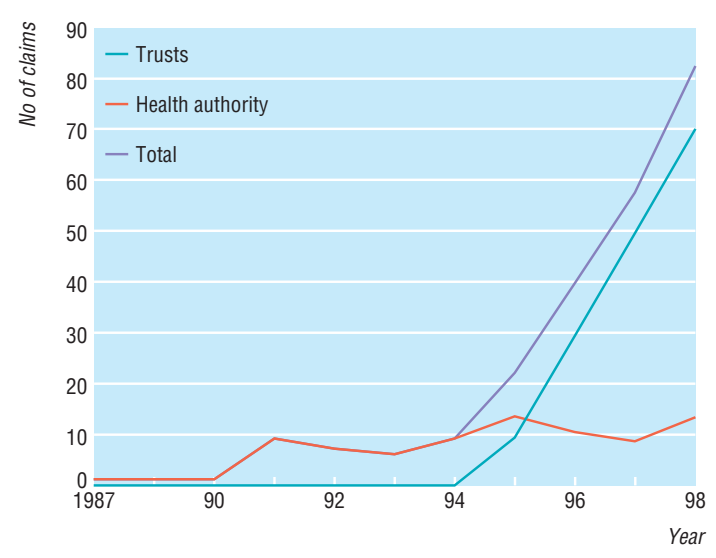

Fig 6 Outstanding claims by year opened, Oxfordshire Health Authority 
plaintiffs and their solicitors in 1998. A more precise estimate of the cost to trusts alone can be produced by using data on the number of paid claims in 1998-9 in a 25\% sample of English trusts referred to above: here the rate of paid claims was 0.24 per 1000 finished consultant episodes (0.22 to 0.26), implying a total payment by trusts in $1998-9$ of $£ 50$ million ( $£ 34$ million to $£ 68$ million).

Defence costs incurred on all claims (paid and unpaid) since 1994 in Oxfordshire averaged $£ 2468$ per closed claim ( $£ 2100$ to $£ 2836$ ). Given the observed rate of 0.81 ( 0.67 to 0.95$)$ closed claims per 1000 finished consultant episodes in 1998, we calculate that the expected defence cost per finished consultant episode was $£ 2.00$ ( $£ 1.40$ to $£ 2.70$ ). This translates to a predicted additional $£ 23$ million ( $£ 16$ million to $£ 31$ million) of defence costs predicted for England in 1998. Our best estimate for the total English NHS clinical negligence cost in 1998 including defence costs is therefore $£ 84$ million ( $£ 48$ million to $£ 130$ million). Some $80 \%$ of this total is estimated to lie with NHS trusts, with the remainder representing the "run off" of health authority liabilities. This mix is rapidly changing, and the next few years will see the trusts' share of total payments for clinical negligence approach $100 \%$.

By contrast, extrapolation of the total cost of outstanding liabilities (that is, currently open claims) yields a figure of about $£ 1.8$ billion for England, of which over three quarters stems from health authority claims that remain open. This is close to the estimate for "contingent liabilities" by the National Audit Office, which, together with an estimate of $£ 1$ billion for "incurred but not reported" claims, has been widely reported as the future "bill to be faced" by the NHS. ${ }^{4}$ In practice, however, the proportion of claims that are eventually paid is quite low, and the estimated settlement cost may be a "worst case" scenario. Moreover, any payments made are spread over a substantial number of years.

\section{Discussion}

Our estimate of the annual cost of clinical negligence litigation is based on a carefully maintained longitudinal database for a defined population. Adjusted for hospital activity, the rate of closed claims increased during the 1990 s by about $7 \%$ per annum, a substantial rate of growth but not the uncontrolled explosion sometimes alluded to.

Our estimate of the total annual cost of clinical negligence litigation-£84 million-takes no account of the administrative costs involved in providing in-house legal services or claims management. Nevertheless, it is a figure well below the amounts quoted in the press for the current cost of settling negligence claims and represents about one quarter of $1 \%$ of annual expenditure on the NHS. Moreover, our estimate is close to that recently reported ( $£ 79$ million) as the amount "paid out in cash in 1997-8" in the fifth report of the public accounts select committee (HC 128, January 2000). It should be noted, however, that neither estimate reflects the impact of recent changes to legal process and the way in which damages are calculated, which will undoubtedly affect mean payments per settled claim and therefore levels of expenditure in future years.

\section{What is already known on this topic}

Hospital negligence claims borne by the NHS were estimated to cost $£ 52.3$ million in the financial year 1990-1, based on a litigation rate of 0.46 closed claims per 1000 finished consultant episodes

\section{What this study adds}

Litigation against the NHS more than doubled in volume between 1990 and 1998, during which time hospital activity increased by $30 \%$

In 1998 there were 0.81 claims closed for each 1000 finished consultant episodes, resulting in an overall expenditure on clinical negligence by the NHS (trusts and health authorities) in the region of $£ 84$ million, including legal costs

Some $80 \%$ of this total was incurred by trusts, and this proportion is growing year by year

The stock of outstanding liabilities, valued at £2.8 billion by the auditor general, is a grossly misleading indicator of the impending cost of clinical negligence to the NHS

There is a need for the NHS to coordinate data sources in relation to the incidence and cost of litigation against trusts and health authorities

We regard estimates of the outstanding liability of the NHS, such as the $£ 2.8$ billion quoted earlier, as deeply misleading. We have shown that this represents the aggregate estimated cost of outstanding claims, most of which will never be paid a single penny and some of which will not be paid for many years, if not decades. There is no way of inferring anything about the likely annual cost of negligence to the NHS from this figure. Moreover, even the more realistic attempts by trusts to calculate the impending cost of negligence, through including as accounting provisions only those claims which are likely to be paid and can be estimated with reasonable accuracy, are fraught with difficulties over the words "likely" and "reasonable." In a recent research project, we uncovered a wide range of discretion with which the decision to provide for particular claims is made. ${ }^{8}$ Until these variations in practice are reduced, it seems that the move in the NHS to commercial accounting on the basis of accruals, together with pay as you go transfer of liability risks to the NHS Litigation Authority, may have confused the picture with respect to the actual resource cost of clinical negligence.

The estimates presented here and the disparity between them and other figures circulating in the medical and general press vividly illustrate the need for more reliable and comprehensive routine statistics to be collated and made available. Until some way is found of coordinating data sources in relation to the incidence and cost of litigation against trusts and health authorities, the estimates presented above are likely to be the most reliable figures available. We do not want to minimise the importance of clinical negligence as a matter of concern to the health service. Indeed, we believe that each claim is potentially a signal to health sector risk 
managers of where they might look for improvements, and it is precisely for this reason that accuracy is essential and that trends are monitored.

Contributors: PF coordinated the study and drafted most of the paper. AG and NR were responsible for the Oxfordshire Health Authority database. SD and RH were responsible for the Chartered Institute of Management Accountants database. PF is the guarantor.

Funding: None

Competing interests: None declared.

Fenn P, Hermans D, Dingwall R. Estimating the cost of compensatin victims of medical negligence. $B M J$ 1994;309:389-91
2 Mawhinney B. Medical negligence claims. House of Commons official report (Hansard) 1994 March 14:239. (No 1648.)

3 Towse A, Danzon P. Medical negligence and the NHS: an economic analysis. Health Econ 1999;8:93-101.

4 Toynbee P. An arm and a leg. Guardian 1999 June 25.

5 National Audit Office. Report of the comptroller and auditor general on the NHS (England) summarised accounts 1996-97. London: Stationery Office, 1998. (HC 923, 21 July 1998.)

6 Office of National Statistics. Key population and vital statistics: local and health authority areas. London: Stationery Office, 1998. (Series VS No 23, PPI No 19.)

7 Office of National Statistics. Regional trends 34. London: Stationery Office, 1999.

8 Fenn P, Diacon S, Hodges R, Watson P. Accounting for risk in the NHS Report to the Chartered Institute of Management Accountants. London: CIMA (in press).

(Accepted 22 February 2000)

\title{
Suicide by patients: questionnaire study of its effect on consultant psychiatrists
}

\author{
David A Alexander, Susan Klein, Nicola M Gray, Ian G Dewar, John M Eagles
}

\begin{abstract}
Objective To identify the effect of patients' suicide on consultant psychiatrists in Scotland.

Design Confidential coded postal questionnaire survey.

Participants Of 315 eligible consultant psychiatrists, $247(78 \%)$ contributed.

Setting Scotland.

Main outcome measures Experience of patient suicide; the features and impact of "most distressing" suicide and what helped them to deal with it.

Results 167 (68\%) consultants had had a patient commit suicide under their care. Fifty four (33\%) reported being affected personally in terms of low mood, poor sleep, or irritability. Changes in professional practice were described by $69(42 \%)$ of the psychiatrists-for example, a more structured approach to the management of patients at risk and increased use of mental health legislation. Twenty four $(15 \%)$ doctors considered taking early retirement because of a patient's suicide. Colleagues and family or friends were the best sources of help, and team and critical incident reviews were also useful.

Conclusions Suicide by patients has a substantial emotional and professional effect on consultant psychiatrists. Support from colleagues is helpful, and professional reviews provide opportunities for learning and improved management of suicide and its aftermath.
\end{abstract}

\section{Introduction}

Stress among doctors has been identified as an important and legitimate occupational health issue. Surveys of general practitioners, ${ }^{1}$ junior house officers, ${ }^{2}$ and hospital consultants ${ }^{3}$ have identified high levels of emotional problems, including "burnout." Consultant psychiatrists have been found to have higher levels of work related exhaustion and depression than physicians and surgeons. ${ }^{4}$ Different work stressors have been identified, including high workload and organisational conflicts, but the impact of suicide by patients, a potentially disturbing event, has not been investigated in the United Kingdom. Although the issue has been studied in the United States, Canada, and New Zealand, ${ }^{5-11}$ many of these studies are limited by the use of small or selective samples, case histories, and anecdotal evidence. We conducted a systematic inquiry into the effect of patients' suicide on a large and non-selected group of senior psychiatrists in Scotland.

\section{Participants and methods}

We sent a confidential questionnaire to all 315 consultant psychiatrists in Scotland identified through the mailing list of the Royal College of Psychiatrists and by cross checks with hospital trusts. The questionnaire was based on a review of the literature, consultation with psychiatric colleagues, and a pilot study. It comprised two sections. The first collected personal information: sex, specialty or subspecialty, number of years in psychiatry, number of years as a consultant psychiatrist, and number of suicides experienced in their consultant careers. The second section required the consultants to identify the "most distressing" suicide they had encountered as a consultant, its professional and personal impact on them, and what helped them to cope.

Throughout the questionnaire there were free text sections. To protect confidentiality, qualitative data were analysed by the non-clinical researchers (SK and NG), who were least likely to recognise any subjects from their replies.

\section{Results}

We received 247 completed questionnaires (a response rate of $78 \%$ ), but not all respondents completed all items. One hundred and fifty six $(63 \%)$ of the respondents were men. The mean number of years in psychiatry was 17.5 (SD 7.2), and the mean number of years as a consultant was 10 (SD 7.8). Sixty nine (28\%) consultants worked in general adult psychiatry, $49(20 \%)$ in old

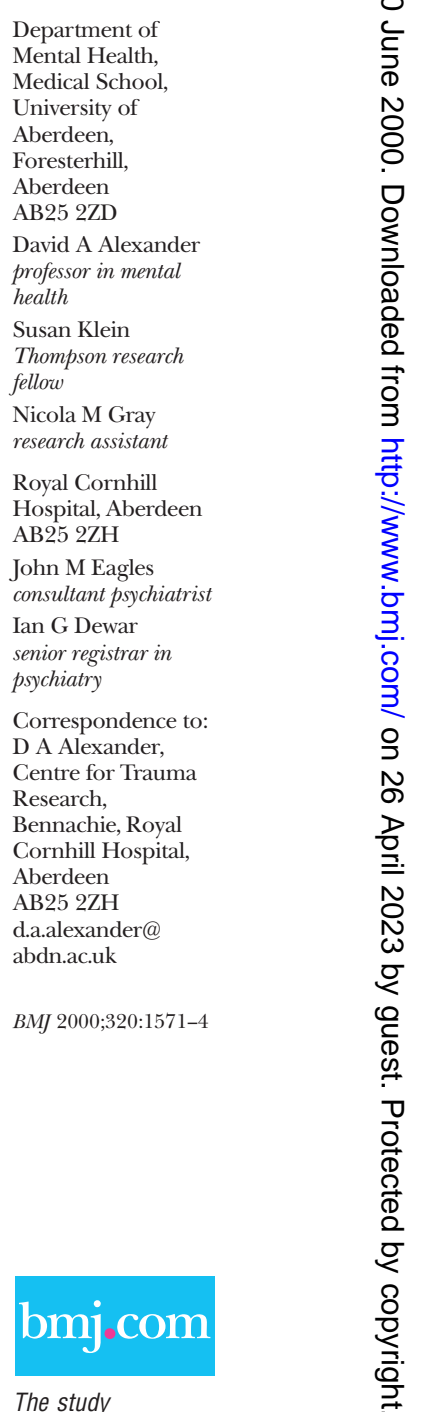
questionnaire is available on the BMJ's website 